Sustainable Development and Planning X 337

\title{
THE IMPLEMENTATION OF LIFE CYCLE ANALYSIS AND SIX SIGMA METHOD TO ACHIEVE SUSTAINABLE WATER CONSUMPTION IN THE AGRICULTURAL SECTOR
}

\author{
KARIN KANDANANOND \\ Faculty of Industrial Technology, Valaya Alongkorn Rajabhat University, Thailand
}

\begin{abstract}
Generally, water is regarded as one of the most important resources in every aspect of life. The reduction of water consumption is a crucial issue for both business and environmental perspectives. This study focuses on the integration of life cycle analysis (LCA), six-sigma, and water footprint method to reduce the water consumption in the agricultural sector. The scenario utilized in this study is the water management in the rice production process. The life cycle analysis and water footprint are used to effectively quantify the water consumption of each production activity covering the analysis scope from cradle to gate. The analysis is based on the type of water footprints which are differentiated into green, blue, and grey. Green and blue water footprint are the rainwater and irrigation water required to grow paddy rice while grey water footprint is the amount of polluted water caused by the production. Afterwards, the main tool of six-sigma, DMAIC (define, measure, analyze, improve, and control), is implemented to reduce the water footprint. The measurement stage shows that the proportion of water use falls in these categories, farm water $(93.4665 \%)$, polluted water $(6.4196 \%)$, transportation $(0.1135 \%)$, and milling $(0.0003 \%)$. Since rice is the semi-aquatic plant so the reduction of farm use water is likely to be impossible, the spotlight is on the polluted water accounted for the second highest water consumption and it is caused by the fertilizer use. Therefore, the cause-and-effect diagram deployed in the analyze phase points out that the utilization of the green manure from the cover crops should be used in conjunction with the tradition fertilizer use. In the improvement phase, after the intervention measure is implemented, through the simulated calculation, the experimental design method statistically shows that the amount of grey water footprint is significantly reduced. To ensure the sustainability of the improvement, the individual X control chart will be applied to monitor the value of grey water footprint in the control stage.
\end{abstract}

Keywords: DMAIC, life cycle analysis, rice, six-sigma, sustainability, water footprint.

\section{INTRODUCTION}

Water is not only the resource needed for human and its scarcity is the global issue on the spotlight of many countries. As a result, there are water saving initiatives introduced in many parts all over the world. Water saving is mostly regarded as the environmental issue and it is always connected to the water security. However, according to the business industry, water is considered as one of the most important resources for the process production, both in service, manufacturing, and agricultural sectors. Moreover, major production cost also involves the utility bill, especially, water. If the water consumption in the organization is significantly reduced, this initiative will lead to the huge amount of cost saving.

Although the reduction in water consumption is known to influence the business operation, it is difficult to implement the saving measures in the organization effectively. One of the main reasons is that the practitioners mostly ignore how to tackle the problem right at the target. Therefore, the water consumption of each process activity should be clearly defined and calculated so the practitioners can make the right decision based on the information regarding the saving implementation. Water footprint is the potential method to quantify the water consumption related to each life cycle activity just like the price tag 
attached to the product so it is the crucial information for the implementation. In Southeast Asia region, the economy substantially relies on the agriculture and rice is considered as one of the major exported crops so it is widely grown overall the region. Water is the main resource of the production of rice. As a result, if the water is consumed efficiently, it will lead to the sustainable consumption of the water in this sector.

Before implementing any measures leading to the water saving, it is important to determine the amount of water consumption for the whole process of production. The life cycle analysis has played an important role of quantifying the water consumption regarding to each production activity while water footprint is proved to be the measurement unit of water consumption. Afterwards, the effective management method will be implemented to tackle the root cause of inefficient consumption. Six Sigma is the tool widely used in the industry since it is the powerful method proved to effectively reduce the variation in the process. Therefore, it is the appropriate tool to be integrated with the life cycle analysis method to reduce the water consumption in the organization. Moreover, another major advantage of the six sigma is its continuous improvement driven mechanism so it is suitable to be utilized as a tool to achieve the sustainable development goals (SDGs). According to SDGs, two major agenda, clean water and responsible consumption, are the global sustainable development goals set by United Nations to be accomplished in 2030. Therefore, in this study, the life cycle analysis, six sigma method, and water footprint are utilized with the attempt to cut down the water consumption in the production process of rice.

\section{LITERATURE REVIEW}

Research by Calzadilla et al. [1] indicates that there is a clear trade-off between the economic welfare due to the water use and the sustainability of environment. Guodong [2] signifies that water footprint is one of the most strategic instruments to achieve the water security, especially, in the agricultural sector. Sadraoui et al. [3] studied the effectiveness of implementing six sigma method in the soft drink factory for the purpose of reducing the water consumption. The result concludes that the implementation leads to the significant saving of the water bill. Six Sigma method is also integrated with the lean initiatives and forms the lean six sigma methodology. There are many studies carried out based on lean six sigma to reduce the environmental waste from the industries. Sarkar et al. [4] have applied lean six sigma in the wind turbine factory to decrease the environmental waste from the manufacturing process. Another combined method is the lean and green which are utilized in many research works. To promote the sustainability in the industry, Parveen et al. [5] have conducted a study to assess the major lean tools used in lean and green supply chain and these tools also include the six sigma method. Franchetti et al. [6] pointed out that six sigma is an important tool for implementing with the lean and green initiatives in the organization, especially, manufacturing enterprises, since the proper utilization will reduce the non-value added waste in the organization efficiently. Sertyesilisik [7] has studied impact of lean and agile method on the reduction of water footprint in the construction industry.

Besides the implementation on water consumption, six sigma method was also used to effectively reduce other types of pollution, e.g. greenhouse gas emission from the manufacturing. This was justified by the work of Sekhar and Mahanti [8] who conducted the study in the foundry manufacturing plant. Kaya and Kahraman [9] also successfully applied the process capability index which is the measurement tool in the six sigma method to monitor the amount of $\mathrm{SO}_{2}$ in the city of Istanbul, Turkey. Calia et al. [10] have studied the effectiveness of the six sigma implementation in many countries and concluded that pollution is significantly effectively prevented in the countries where six sigma is sporadically implemented in the industrial sector. Cherrafi et al. [11] has reviewed the appropriate model 
of integrating the lean manufacturing and six sigma method to achieve the sustainability. The detailed study conducted by Cherrafi et al. [12] indicates that the implementation of six sigma method in the industries is able to reduce resources consumption from 20 to 40 percent and minimize the cost of energy and mass streams by 7 to 12 percent. Therefore, six sigma method is one of the most appropriate tools to be implemented in order to achieve the environmental sustainability.

\section{RESEARCH METHODOLOGY}

Life cycle analysis (LCA) is the assessment technic to quantify the environmental effect (exchange flows between the system and the ecology) for all stages of the entire life of a product or process. This is accounted from the resource extraction to the end of its life cycle. Six sigma is a management strategy which aims to improve the process quality. The main purpose of six-sigma is to identify and remove the causes of variability in the processes. The project methodology of six-sigma is divided into five phases, DMAIC, define, measure, analyze, improve, and control. Define is a starting step which states the problem definition while measure is the stage where the as-is process is measured. Analyze is the step when cause and effect are identified and the improve stage is the intervention which is implemented to improve process. Control is the last step which is done to ensure the sustainability of the improvement.

The water footprint method is initially introduced by Hoekstra and Chapagain in 2007 to signify the amount of water consumed for the production of services and commodities. The purposes of water footprint are differentiated into four categories, the measurement of water consumption, the identification of environmental influence in term of numerical results due to the consumption, the risk assessment regarding the consumption, and the introduction of strategies leading to the reduced consumption.

\section{SCENARIO}

Rice is the crop widely grown in Southeast Asian countries including Thailand which is among the top rice exporters in the world. A large amount of water is required to grow rice. To achieve the water sustainability in the country, it is important to elaborately study the water consumption of the production process. As a result, to facilitate the study, the analysis and experiment were conducted in a demonstration farm located in a public University and the size of the field is about 1 rai or 0.16 hectare. The main crop grown in the farm is the paddy rice. Rice is the semi-aquatic crop so water is the main resource required. Since the source of water comes from both rainwater and irrigation water, there are two types of water footprint, i.e. blue and green, to be calculated. Moreover, another aspect of water consumption is the amount of water polluted because of the production process. To initiate the water consumption study, the study on water source is conducted. The main supply of irrigation water in the central area of Thailand is Chao Praya river. Figs 1 and 2 show the paddy rice field in two phases, vegetative and ripening.

\section{RESEARCH RESULTS}

The water consumption from different stages of rice production is analyzed by using the life cycle analysis. The scope of the analysis is cradle to gate, i.e., the whole process of production until the rice is ready to be delivered to customers. After the life cycle analysis was carried out, the six sigma method is implemented to analyze and effectively reduce the water footprint. 


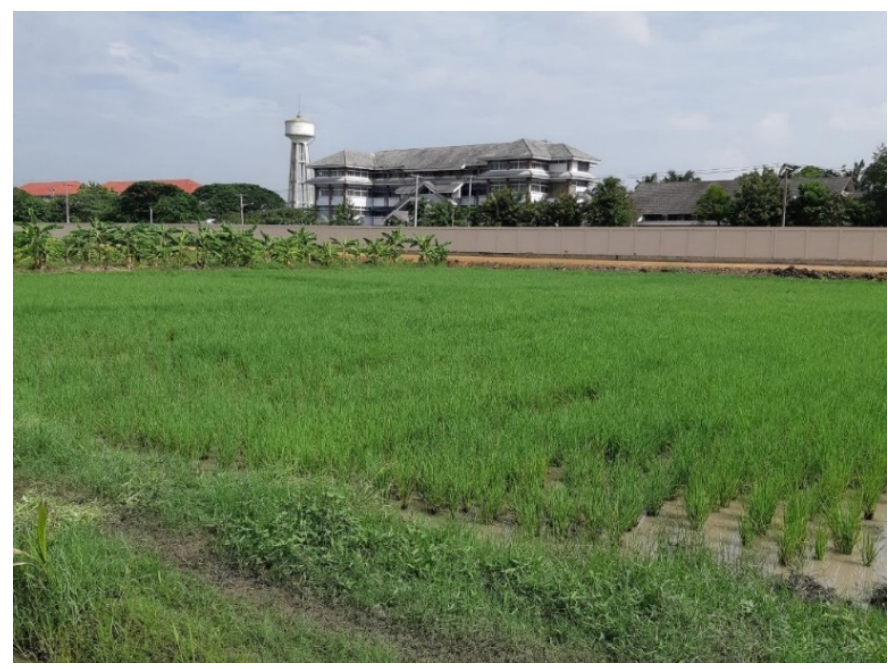

Figure 1: Vegetative phase.

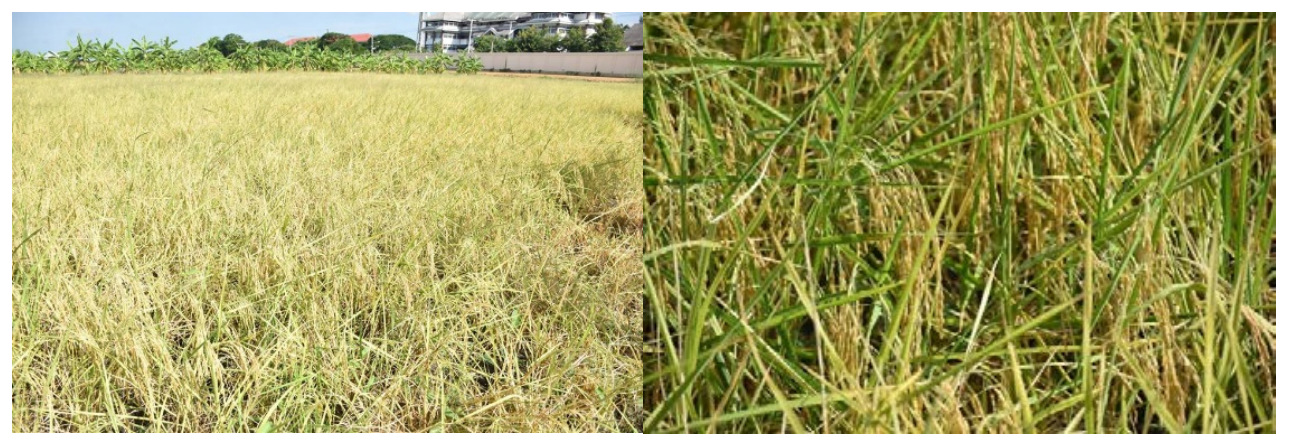

Figure 2: Ripening phase.

\subsection{Life cycle analysis}

To accurately quantify the water consumption, the life cycle analysis (LCA) is used to analyze the water consumption related to each activity of the life cycle. Since the main water supply of rice is from two sources, rainwater and irrigation water, according to Silalertruksa et al. [13], the relationship between rice yield and water use is shown in Table 1.

Because the rice yield from the demonstration farm is $505 \mathrm{~kg}$, the total water footprint for the cultivation is shown in Table 2.

Table 1: Water footprint and rice yield.

\begin{tabular}{|c|c|}
\hline Source & Footprint (cubic meter $/ \mathrm{kg}$ ) \\
\hline Rainwater & 1.08 \\
\hline Irrigation water & 0.35 \\
\hline
\end{tabular}


Table 2: Total water consumption for rice yield.

\begin{tabular}{|c|c|}
\hline Source & Water consumption (cubic meter) \\
\hline Rainwater & 545.4 \\
\hline Irrigation water & 176.75 \\
\hline Total & 722.15 \\
\hline
\end{tabular}

Therefore, the total amount of water consumption for growing rice is cubic meter (yield is $505 \mathrm{~kg}$ ). The rice production does not only consume rainwater and irrigation water but also polluted the water. Because the application of Nitrogen fertilizer is important for the soil fertility which will result on the consistent productivity of the farm. However, it also pollutes the water. Therefore, it contributes to another type of water footprint, grey water footprint. The grey water footprint is calculated in eqn (1). The calculated grey water footprint is equal to 49.6 cubic meter

$$
\mathrm{GWF}=\mathrm{R} * \mathrm{~L} / \mathrm{L}_{\text {crit }},
$$

where $\mathrm{R}$ is the runoff of the water body (volume/time)

$\mathrm{L}$ is the pollutant load entering a water body (mass/time)

$\mathrm{L}_{\text {crit }}$ is the critical pollutant load entering a water body (mass/time).

Another stage of LCA to be considered is the transportation of rice to be milled. A fourwheel truck will be used to deliver the harvested rice to be milled. The one-way distance from the farm to the milling plant is $6.9 \mathrm{~km}$ so the round-trip distance is $13.8 \mathrm{~km}$.

The fuel used in the vehicle is diesel and the amount of fuel consumption for the distance is 1.53 liter. The water footprint calculation is shown in Table 3 and the total water consumption for the production of the fuel is 0.877 cubic meter.

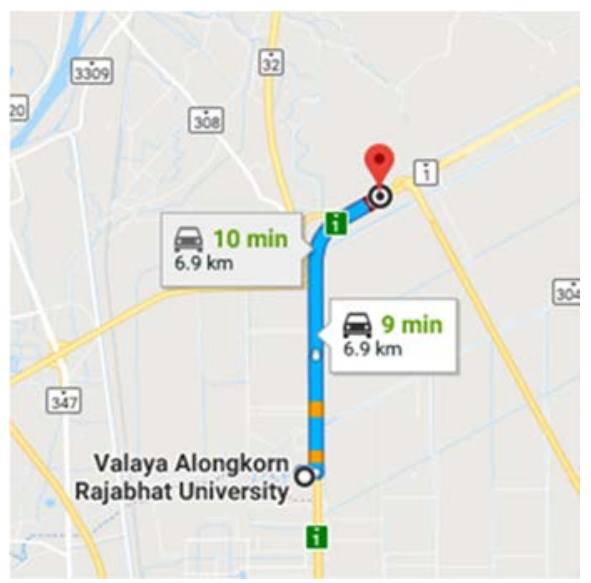

Figure 3: Traveling distance between the rice field and rice mill plant.

Table 3: Water footprint due to fuel use.

\begin{tabular}{|c|c|c|c|c|c|c|}
\hline Fuel & $\begin{array}{c}\text { Density } \\
(\mathrm{kg} / \text { liter })\end{array}$ & $\begin{array}{c}\text { Fuel used } \\
(\text { liter })\end{array}$ & $\begin{array}{c}\text { Fuel used } \\
(\mathrm{kg})\end{array}$ & $($ Liter $/ \mathrm{kg})$ & $\begin{array}{c}\text { Water footprint } \\
\text { (Liter) }\end{array}$ & $\begin{array}{c}\text { Water footprint } \\
\text { (cubic meter) }\end{array}$ \\
\hline Diesel & 0.832 & 1.53 & 1.272 & 690 & 877 & 0.877 \\
\hline
\end{tabular}


Harvested rice was milled by using a machine which is the capability of $40 \mathrm{~kg}$ per hour so the total hours are 12.6. Therefore, the electricity consumption is $9.45 \mathrm{kWh}$. Since the water consumption on the electricity generation is 0.26 liter/MWh, the water footprint for the electricity is 0.002457 cubic meter.

\subsection{Six-sigma implementation}

The reduction of water consumption is based on the application of six-sigma method, which are categorized into five stages, define, measure, analyze, implement, and control (DMAIC).

\section{Define}

Obviously, the focused problem is the reduction of water consumption used in the production process of rice. According to the LCA of rice production process, the amount of water footprint per one season of crop growing in the demonstration farm is shown in Table 4.

\section{Measure}

The life cycle analysis of rice production regarding the water consumption is divided into four stages, farm water, polluted water (due to the fertilizer use), transportation and milling process. According to the chart depicting the LCA, the majority of water use falls into the category of farm water which is accounted for 93.4665 percent. The second highest footprint is caused by the fertilizer use (6.4196 percent). However, the footprints due to the transportation and milling process are very low (less than 1 percent). Therefore, the intervention measure should be implemented to reduce the amount of farm water use since it is contributed to the highest water use. However, since rice is the semi-aquatic plant which requires a lot of water to grow, it is not likely to reduce the farm water use. Therefore, the second highest water use in the LCA, i.e., polluted water, is the main target to be improved.

\section{Analyze}

The cause-and-effect diagram in Fig. 5 is utilized to reduce the grey water footprint. Due to the brainstorming by the experts, there are four alternatives for reducing grey water footprint, water treatment, growing cover crops, manure use, and fertilizer use reduction. Elaborately, water treatment is accomplished by using water filtration. On the other hand, two types of cover crops, pummelo and peanuts, are recommended to use as the green manure. Manure use includes animal and compost.

To select the most appropriate alternative, each option is assessed by following two categories, the likeliness of being the major source of the issue and the level of easiness to implement. The levels of source likeliness are differentiated into three levels, very likely, somewhat likely, and not likely. Likewise, the levels of implement easiness are divided into very easy, somewhat easy, and not easy. If any proposed option passes the screening test, it should get the green light to be implemented.

Table 4: Total water consumption in each LCA stage.

\begin{tabular}{|c|c|c|}
\hline LCA stage & Water consumption (Cubic meter) & Type of water footprint \\
\hline Farm water & 722.15 & Blue and green \\
\hline Transportation & 0.877 & Blue \\
\hline Mill & 0.002457 & Blue \\
\hline Fertilizer use & 49.6 & Grey \\
\hline Total & 772.629457 & \\
\hline
\end{tabular}




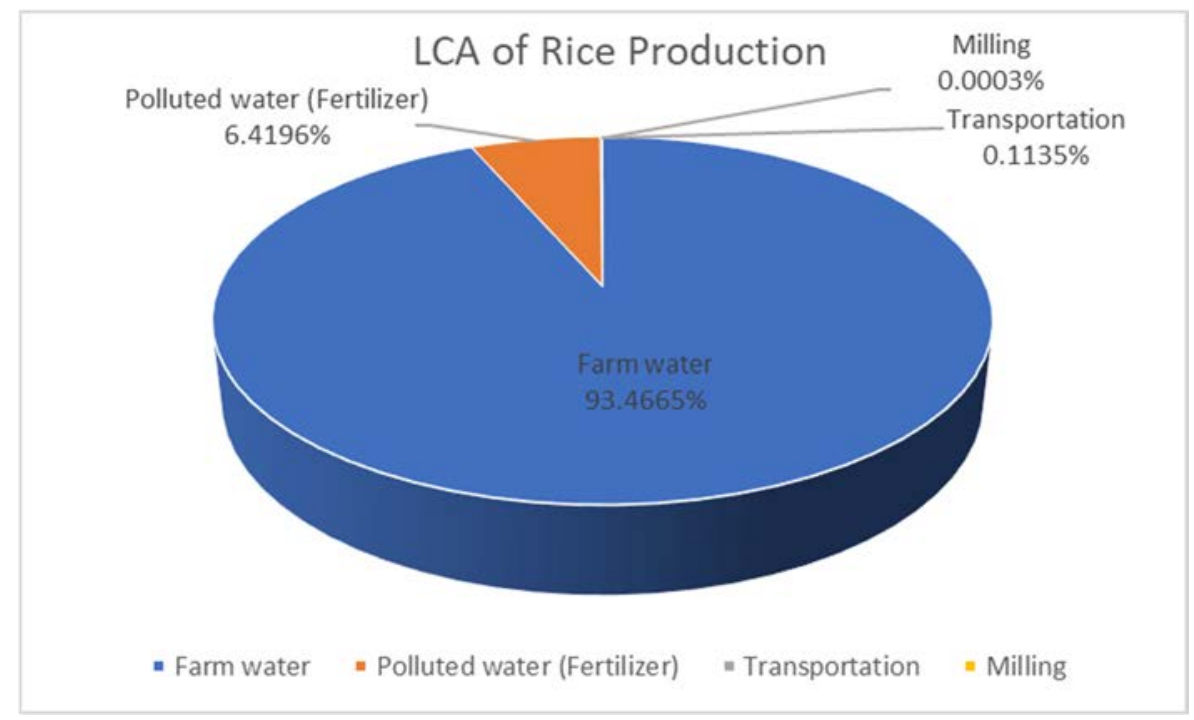

Figure 4: Life cycle analysis of rice production.

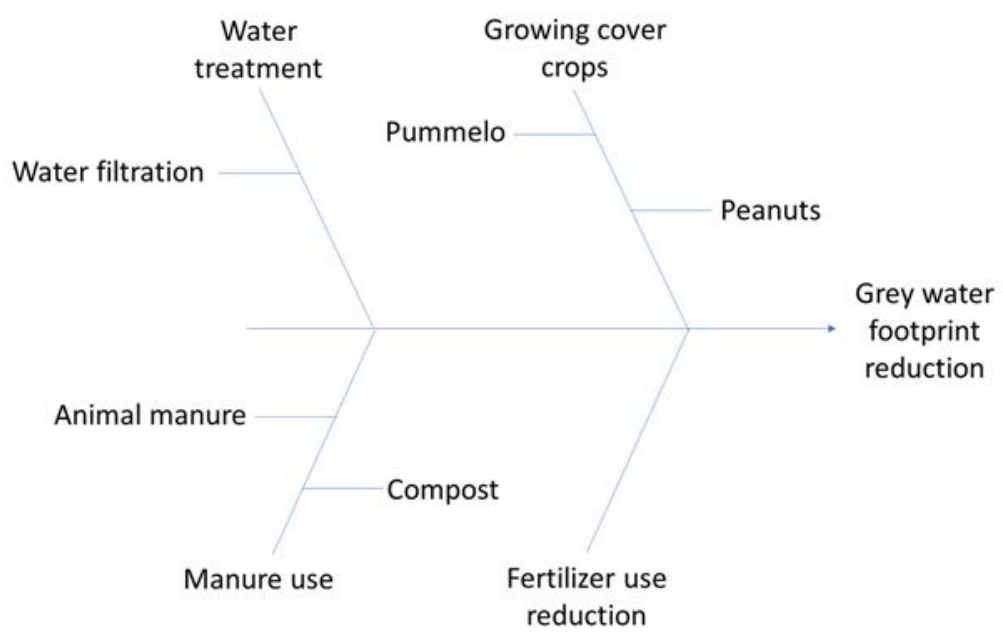

Figure 5: Cause-and-effect diagram.

According to Table 5, each alternative is listed with the assessment in the above mentioned categories. Due to the experts, the cover crops is the preferred option to others since it is rated as "somewhat likely" due to the source likeliness while it is quite easy to be implemented. However, although water treatment is "somewhat likely" to be major source, it is not easy to be applied because it needs a lot of investment for filtration system. Likewise, manure use (animal and compost) is not believed to reduce the amount of polluted water even they are easy to practice. Lastly, the reduction of fertilizer use might affect the productivity of the crop yield so it is not the preferred option too. 
Table 5: Intervention and their competency outcome.

\begin{tabular}{|c|c|c|c|c|c|c|}
\hline \multirow{2}{*}{ Intervention } & \multicolumn{3}{|c|}{$\begin{array}{c}\text { The likeliness of being the major } \\
\text { source of the issue }\end{array}$} & \multicolumn{3}{|c|}{$\begin{array}{c}\text { The level of easiness to } \\
\text { implement }\end{array}$} \\
\cline { 2 - 7 } & Very likely & $\begin{array}{c}\text { Somewhat } \\
\text { likely }\end{array}$ & $\begin{array}{c}\text { Not } \\
\text { likely }\end{array}$ & $\begin{array}{c}\text { Very } \\
\text { easy }\end{array}$ & $\begin{array}{c}\text { Somewhat } \\
\text { easy }\end{array}$ & Not easy \\
\hline $\begin{array}{c}\text { Water } \\
\text { treatment }\end{array}$ & & $\mathrm{X}$ & & & & $\mathrm{X}$ \\
\hline $\begin{array}{c}\text { Growing } \\
\text { cover crops }\end{array}$ & & $\mathrm{X}$ & & $\mathrm{X}$ & & \\
\hline Manure & & & $\mathrm{X}$ & $\mathrm{X}$ & & \\
\hline Fertilizer use & & & $\mathrm{X}$ & $\mathrm{X}$ & & \\
\hline
\end{tabular}

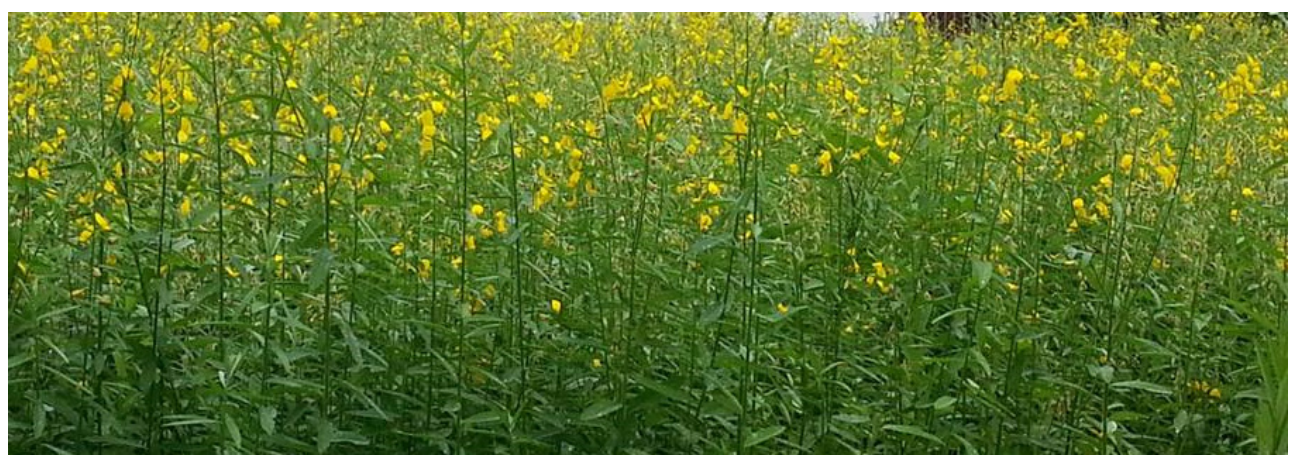

Figure 6: Pummelo.

As a result, the option of growing cover crops is selected since the application of cover crops as the green manure will help to enrich the nutrient, especially, Nitrogen in the soil which is important for the growth of paddy rice. Two types of cover crops, pummelo and peanuts, are considered to be grown. It is interesting to note that growing pummelo (Fig. 6) is highly likely to reduce the amount of polluted water.

Generally, it will be grown after the harvest season and ploughed when their flowers are fully bloom. It is known as the natural fertilizer or green manure. The residue left in the field has contributed to a significant amount of the nutrients required for the paddy rice. Moreover, this approach is quite easy to implement since pummelo can grow easily after their seeds are planted in the field. According to the study, the pummelo in 1 rai (or 0.16 hectare) is equivalent to fertilizer formula 46-0-0 for the amount of $15 \mathrm{~kg}$ which is enough for the growth of paddy rice.

\section{Improve}

In the improvement phase, pummelo will be grown on the field before the next cropping season. The experimental design technique is used to study the impact of pummelo on the amount grey water footprint. Therefore, the rice field is divided into four fields as shown in Fig. 7. pummelo will be grown as the cover crop fertilizer in two fields (No. 1 and No. 2 pummelo crop) while fertilizer was used in the other two fields (No. 1 and No. 2 Fertilizer). The grey water footprint data $\mathrm{w}$ collected from these four fields will be simulated and statistically analyzed. The result shows that the utilization of pummelo as the cover crop 
fertilizer is able to reduce the amount of grey water significantly (p-value $=0.000$ ). The average grey water footprint from the rice growing by using two types of fertilizers is shown in Fig. 8. Since there is no overlap between the average values of grey water footprint of these two treatments, it explicitly signifies that there is a significant difference between the water footprints after these two different methods are utilized.

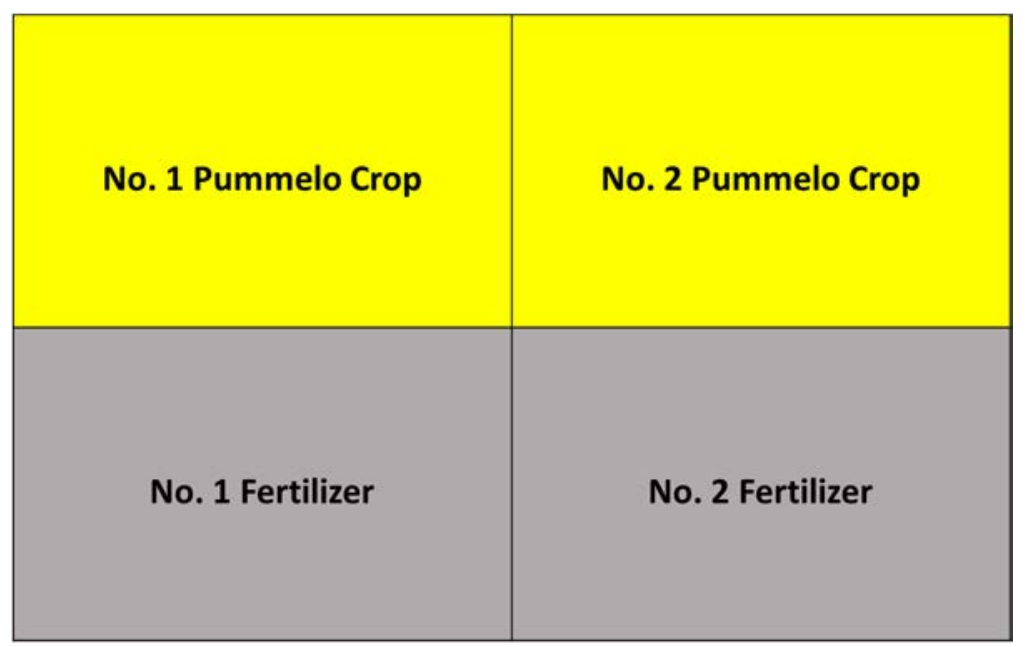

Figure 7: Proposed experimental field.

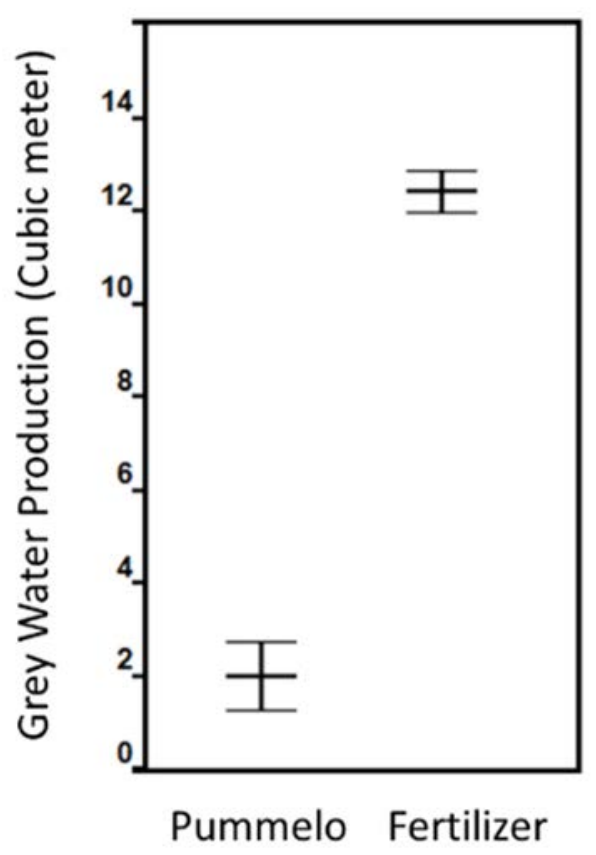

Figure 8: Projected grey water footprint of different treatments. 
5. Control

The control stage is the phase where certain measures are implemented to ensure the sustainable control of the grey water footprint after the improvement is implemented. It involves the measures to monitor the value of the grey water footprint. The statistical tool used is the control chart, individual $\mathrm{X}$, which has the upper and lower control limit (UCL)

Upper control limit: $\bar{x}+3 \overline{M R} / 1.128$

Center line: $\bar{x}$

Lower control limit: $\bar{x}-3 \overline{M R} / 1.128$

$$
\bar{x}=\sum_{i=1}^{m} \frac{x_{i}}{m}, \overline{M R}=\left|x_{i}-x_{i-1}\right|,
$$

where: $\mathrm{x}_{\mathrm{i}}$ is the water footprint at season $\mathrm{i}$

$\mathrm{m}$ is the number of season.

Since there are two growing seasons (April and October 2018) going on, the control chart depicts only two simulated values of grey water footprint from these two seasons. The upper and lower control limits are based on the initial value since there are no historical data.

If the value of grey water footprint is still in the range of upper and lower control limit, it explicitly means that this value is in control, i.e., the control continuous improvement is effective.

\section{Chart for Grey Water Footprint}

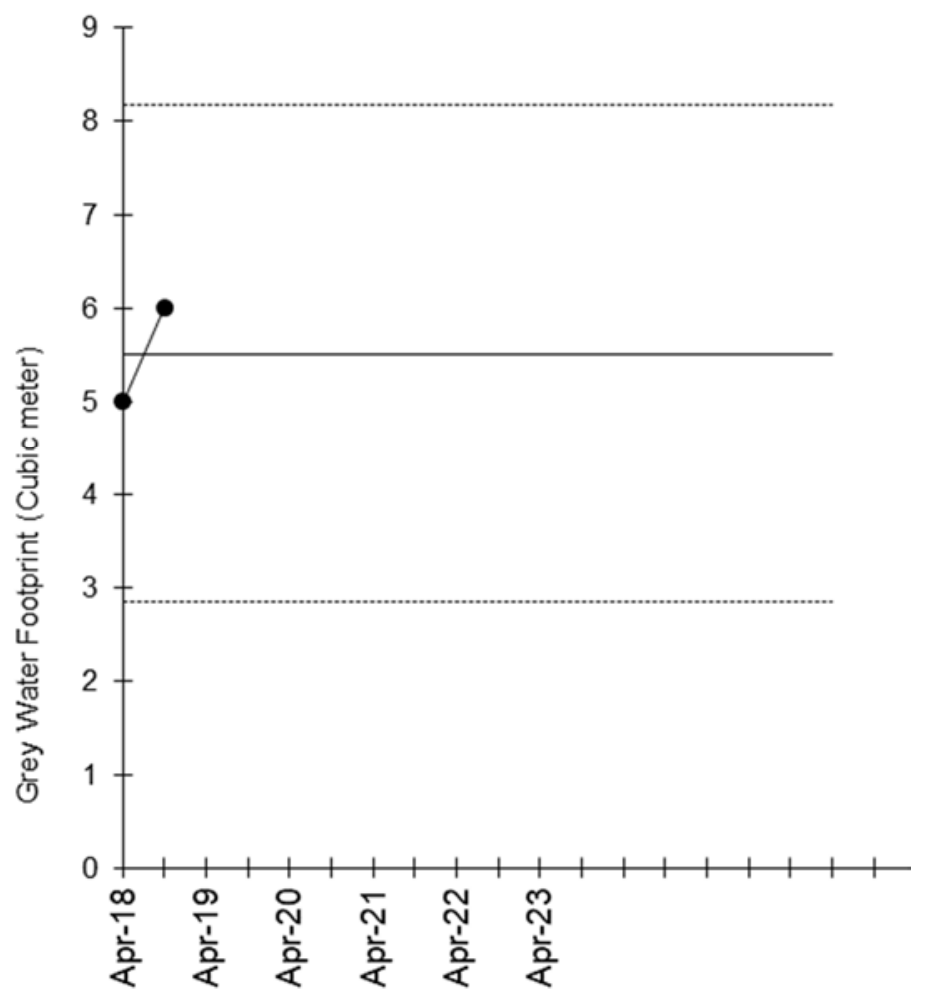

Figure 9: A control chart for monitoring grey water footprint. 


\section{CONCLUSIONS AND DISCUSSIONS}

The life cycle analysis of the rice production is assessed by considering the water consumption in each stage. The assessment result indicates that the major source is the water used for nurturing the rice. However, because the rice growth mainly depends on the water supply, it is not likely to reduce the water use in this category. Therefore, the initiative is switched to the second source which is the polluted water. Since fertilizer is the source of the pollution, the amount of fertilizer use should be reduced. As a result, a six-sigma tool, DMAIC, is applied with the attempt to reduce the fertilizer use. The analysis phase points out that the green manure (growing cover crops) should be utilized to reduce use of chemical fertilizer. Pummelo is the plant chosen to grow as cover crops in the paddy rice field in the improvement phase. The final result show that the green manure can replace the fertilizer use completely. Anyway, another advantage of DMAIC implementation is the achievement of the sustainability since the monitoring tool will be used in the control phase to ensure the value of grey water footprint to be in the acceptable range.

In conclusion, the application of water footprint greatly influences the successful saving of water consumption since it has the capability of quantification. Practitioners are always adhered to the quantified amount related to each activity, so they know exactly their contribution to the water consumption. On the other hand, six-sigma is a quality management technique which is widely used in the service and manufacturing sector. However, this study proves that it can also be implemented successfully in area of the agricultural management.

\section{REFERENCES}

[1] Calzadilla, A., Rehdanz, K. \& Tol, R.S.J., Water Scarcity and the Impact of Improved Irrigation Management: A CGE Analysis, Kiel Institute for the World Economy, 2008.

[2] Guodong, C., Virtual water-a strategic instrument to achieve water security. Bulletin of the Chinese Academy of Sciences, 2004.

[3] Sadraoui, T., Afef, A. \& Fayza, J., Six Sigma: a new practice for reducing water consumption with coca cola industry. International Journal of Six Sigma and Competitive Advantage, 9(2), pp. 217-244, 2012.

[4] Sarkar, A., Mukhophadhay, A.R. \& Ghosh, S.K., Addressing environmental concern through lean Six Sigma - a greener approach. Sustainable Waste Management, pp. 7176, 2011.

[5] Parveen, C.M., Kumar, A.R.P. \& Rao, T.V.V.L.N., Integration of lean and green Supply chain-impact on manufacturing firms in improving environmental efficiencies. Proceedings of International Conference on Green Technology and Environmental Conservation, 2011.

[6] Franchetti, M., Bedal, K., Ulloa J. \& Grodek, S., Lean and green: industrial engineering methods are natural stepping stones to green engineering. Industrial Engineer, 41(9), 24-29, 2009.

[7] Sertyesilisik, B., Lean and Agile Construction Project Management: as a way of reducing environmental footprint of the construction industry. Intelligent Systems, Control and Automation: Science and Engineering, 72, pp. 179-196, 2014. DOI: 10.1007/978-94-017-8044-5_11.

[8] Sekhar, H. \& Mahanti, R., Confluence of Six Sigma, simulation and environmental quality: an application in foundry industries. Management of Environmental Quality: An International Journal, 17(2), pp. 170-183, 2006.

DOI: $10.1108 / 14777830610650483$. 
[9] Kaya, I. \& Kahraman, C., A new tool for risk assessment of air pollution: Fuzzy process capability indices. Human and Ecological Risk Assessment: An International Journal, 17(3), pp. 613-630, 2011. DOI: 10.1080/10807039.2011.571090.

[10] Calia, R.C., Guerrini, F.M. \& De Castro, M., The impact of Six Sigma in the performance of a pollution prevention program. Journal of Cleaner Production, 17(15), pp. 1303-1310, 2009. DOI: 10.1016/j.jclepro.2009.05.001.

[11] Cherrafi, A., Elfezazi, S., Chiarini, A., Mokhlis, A. \& Benhida, K., The integration of lean manufacturing, Six Sigma and sustainability: a literature review and future research directions for developing a specific model. Journal of Cleaner Production, 139, pp. 828-846, 2016. DOI: 10.1016/j.jclepro.2016.08.101.

[12] Cherrafi, A., Elfezazi, S., Govindan, K., Garza-Reyes, J.A., Benhida, K. \& Mokhlis, A., A framework for the integration of Green and Lean Six Sigma for superior sustainability performance. International Journal of Production Research, 55(15), pp. 4481-4515, 2017. DOI: 10.1080/00207543.2016.1266406.

[13] Silalertruksa T., Gheewala, S.H., Mungkung, R., Nilsalab, P., Lecksiwilai, N. \& Sawaengsak, W., Implications of water use and water scarcity footprint for sustainable rice cultivation. Sustainability, 9(12), pp. 2283-2296, 2017. DOI: 10.3390/su9122283. 